\title{
Inclusão como matriz de experiência
}

Maura Corcini Lopes*, Juliane Marschall Morgenstern**

\section{Resumo}

Ao problematizar a inclusão a partir dos impactos da teorização foucaultiana no campo da Educação, o artigo propõe um exercício de desconstrução de práticas que constituem a inclusão como "foco" ou "matriz de experiência", no cenário brasileiro contemporâneo. Tomando a governamentalidade como grade de inteligibilidade em que se inscrevem as práticas inclusivas, operou-se com o governamento e a subjetivação como ferramentas teórico-metodológicas para o tensionamento preten-

* Universidade do Vale do Rio dos Sinos (UNISINOS), São Leopoldo, RS, Brasil. maurac@terra.com.br

** Universidade do Vale do Rio dos Sinos (UNISINOS), São Leopoldo, RS, Brasil. Bolsista Capes/Proex. jujucamorg@yahoo.com.br dido. Ficou visível que, ao investir na subjetivação dos indivíduos, a matriz de experiência da inclusão torna-os capazes de aliar, no domínio de si, práticas de sujeição e práticas de liberdade. 0 agonismo da conjugação de tais práticas, ao capturar e submeter o indivíduo à matriz de experiência da inclusão, também possibilita condições para o exercício da contraconduta, de modo a alterar ou deslocar as formas de condução para a inclusão vivida até o presente e forjar subjetividades outras, até então impensadas.

\section{Palavras-chave}

Inclusão, matriz de experiência, estudos foucaultianos, contraconduta. 


\title{
Inclusion as Matrix of Experience
}

\begin{abstract}
In order to problematize inclusion practices in the light of Foucault's theorizing in the field of education, the article proposes an exercise of deconstruction of the practices that treat inclusion as a focus or matrix of experience in contemporary Brazil. Taking governmentality as a grid of intelligibility of inclusive practices, the concepts of governance and subjectivity were used as theoretical and methodological tools for the analysis. It became apparent that, by investing in the subjectivity of the individuals, the matrix of experience of inclusion makes them able to ally, in the domain of self, practices of subjection and practices of freedom. The agonism of the combination of such practices, capturing and submitting the person to the matrix of experience of inclusion, also provides conditions for the exercise of counterconduct in order to change current practices of inclusion and to forge hitherto unthought-of subjectivities.
\end{abstract}

Keywords Inclusion, matrix of experience, foucauldian studies, contraconduta. 


\section{Introdução}

Michel Foucault, em seus textos, não se ocupou, especificamente, da Educação. Porém, o legado de teorizações deixadas por ele permite que reconheçamos, graças à centralidade do sujeito em suas investigações, o papel da Educação na fabricação dos sujeitos. Sua obra - ao mostrar a preocupação com a constituição do sujeito, ao estabelecer distinções entre modos de sujeição e modos de subjetivação e ao renunciar à pretensa universalidade do sujeito - dá ênfase às práticas constitutivas da experiência. Isso significa, entre outras coisas, que práticas de sujeição, ao partirem de um "certo número de regras, de estilos, de convenções que podemos encontrar no meio cultural” (Foucault, 2004, p. 291), subjetivam os indivíduos e os constituem como sujeitos capazes de conjugar em si tanto as práticas de sujeição quanto as de liberdade. Assim, se o problema do sujeito ocupa o centro das preocupações de Foucault, podemos traçar produtivas interfaces entre suas teorizações e as diferentes práticas educativas. Então, embora o filósofo não tenha se voltado declaradamente para a Educação, as questões propostas por ele e que tensionam as formas de condução da conduta e as formas pelas quais os indivíduos se tornam sujeitos guardam uma relação de imanência com a Educação. Talvez aí resida o imenso impacto de Foucault no campo educacional.

O convite deste dossiê é para que pensemos os impactos de Foucault na Educação. Para tanto, não faremos aqui um levantamento de produções que se ocupam da Educação, pois quanto a isso já contamos com profícuas e interessantes investidas, como, entre outras, a de Aquino (2013). Propomos fazer um exercício de desconstrução de práticas que constituem o nosso presente e aquilo que somos; mais especialmente, de práticas que constituem a inclusão como uma "matriz de experiência" contemporânea. Para tanto, organizamos este texto em dois momentos, cada um com seu eixo argumentativo: teorizações foucaultianas que permitem pensar a inclusão como matriz de experiência e a inclusão como matriz de experiência, em que se articulam saber, poder e subjetivação.

\section{Ferramentas foucaultianas para pensar a inclusão e a Educação}

Nos cursos Segurança, território e população (1978) e Nascimento da biopolítica (1979), Michel Foucault forneceu potentes ferramentas para pensarmos as relações de poder e as tecnologias que tornam possíveis o governo e a condução dos outros e de si mesmo. Ao concentrar seu interesse nas práticas de governamento - que tanto organizam instituições quanto permitem regular e normatizar condutas individuais -, 
o filósofo criou o conceito de "governamentalidade" como uma grade de inteligibilidade capaz de nos fazer entender a emergência de uma razão de Estado. Decorrente de tal entendimento, Foucault articulou, na governamentalidade, tanto tecnologias de governamento quanto tecnologias de subjetivação. Ambas são cruciais para compreendermos a ação da Educação sobre os indivíduos e sobre a população ${ }^{1}$.

É interessante observar o cuidado que teve Foucault (2008a, 2008b), ao traçar a genealogia do liberalismo e do neoliberalismo, em diferenciar as práticas de resistência das práticas de contraconduta, como formas próprias de condução das racionalidades liberal e neoliberal. O filósofo mostrou que ambos os tipos de práticas não surgem necessariamente como (neo)liberais; mas, quando emergem, geram tensões e podem exigir novas configurações políticas para a condução dos indivíduos. Voltaremos a este assunto na próxima seção, ao argumentar que, pela inclusão ou pela situação de estar no mesmo espaço físico, temos determinadas condições para que se criem outras formas de nos relacionar e, talvez, de nos surpreender com nossas próprias condutas.

Nos cursos Do governo dos vivos (1980), A hermenêutica do sujeito (1982), O governo de si e dos outros (1983), entre outros escritos de Foucault da década de 1980, a ênfase recai sobre as formas de sujeição e de subjetivação, ou seja, sobre as formas pelas quais os indivíduos se tornam sujeitos a partir das tecnologias de dominação de si e sobre as formas de obtenção da subjetividade. Rago (2013), ao utilizar ferramentas foucaultianas para tratar dos feminismos e das artes do viver a escrita de si, retoma algo bastante útil para as reflexões aqui desenvolvidas: a constituição do individuo ético e as artes da existência. A autora relembra que, para Foucault, o "sujeito não é condição de possibilidade da experiência, não preexiste aos acontecimentos; ao contrário, constitui-se na ação e em redes de relações em que vivencia a experiência” (Rago, 2013, p. 42).

Nos interesses que mobilizavam Foucault nos anos de 1980, o autor deslocou seu interesse dos dispositivos do saber-poder e das tecnologias de dominação dos outros (enfatizados nos cursos de 1976 até 1979) para o governo pela verdade. Ao fazer a história da subjetividade, ele usa tecnologias de dominação de si capazes de convencer os sujeitos a governarem-se pela verdade. Fazendo uma leitura transversalizada

1. Para uma revisão e discussão minuciosas acerca dos usos da palavra "governo" e suas derivadas, vide Veiga-Neto (2002). da obra do autor, é possível visualizar, ocupando o centro de suas preocupações nos cursos de 1980,principalmente nos cursos de 1983 e 1984 -, as 
práticas ou o que chamou, no curso Do governo dos vivos (1980), de "focos de experiência”. Para Foucault, a loucura, a sexualidade, a criminalidade, a doença, etc. constituem focos de experiências ou modos de existência virtuais para sujeitos possíveis (Foucault, 2010b).

Voltando para o que interessa neste artigo, ou seja, para a inclusão e a Educação, argumentamos que, nas últimas duas décadas, no Brasil, a inclusão pode ser entendida como um "foco" ou uma "matriz de experiência" que conjuga saberes, poder e formas de subjetivação específicas de nosso tempo (Foucault, 2010b). Assim, é possível tomarmos emprestado de Foucault a interpretação que ele faz do governo pela verdade, para podermos ler e tensionar as muitas formas aletúrgicas que conduzem os indivíduos a se converterem à inclusão como uma verdade boa e como uma condição necessária para que todos possam usufruir de direitos mais equânimes de vida. Desse modo, interessa-nos ver as manifestações da verdade sobre a inclusão. Tais manifestações se dão num conjunto de procedimentos verbais e não verbais, em enunciações de distintas bases epistemológicas e em rituais que apresentam, enfaticamente, ritos de passagem, experiências individuais de conquistas e superações dos assim denominados incluídos, bem como daqueles que se relacionam com eles no vasto campo da Educação e da Pedagogia.

Assim, neste artigo, nos utilizamos do entendimento de "governamentalidade" e, compondo tal grade de inteligibilidade, das ferramentas teórico-metodológicas do governamento e da subjetivação para poder tensionar a inclusão, a partir do campo da Educação, como um "foco" ou "matriz de experiência” contemporâneo. Para tanto, entre outras passagens mais rápidas de rituais do presente, traremos excertos de políticas e documentos produzidos em caráter oficial, que fazem parte de uma pesquisa mais abrangente e que servem para mostrar a produtividade das ferramentas foucaultianas para o campo da Educação.

Feitos esses esclarecimentos sobre as ferramentas conceituais que permitem tensionar a inclusão, passamos a tematizar de forma mais detida a inclusão educacional como matriz de experiência.

\section{Inclusão: uma matriz de experiência para tensionar o presente}

Ao tomarmos a análise que Foucault realiza da constituição da loucura como experiência - na convergência daquilo que o autor chamou de for-

1. No curso O governo de si e dos outros, Foucault (2010b) utiliza "matriz de experiência" ou "foco de experiência" como sinônimos. 
mas de saber possível, normativas de comportamento e modos de existência virtuais para sujeitos possíveis -, encontramos a noção de "foco de experiência” ou “matriz de experiência”, que nos permite aproximá-la de uma estética da existência³. Trata-se de uma estética que, a nosso ver, assume diferentes contornos, até cristalizar-se como forma de vida transformada no presente.

Nessa direção, perguntamos pela inclusão a partir das três dimensões que a constituem como uma experiência imbricada no interior de certa cultura, cujo interesse aqui se volta ao cenário cultural brasileiro nos últimos 20 anos, aproximadamente. No primeiro eixo ou dimensão, procuramos olhar para a inclusão, tecendo uma análise do desenvolvimento de uma série de saberes, mais ou menos heterogêneos que, formados a partir de um ponto comum a integram e a compõem. No segundo eixo, cabe considerar que, sendo uma forma de saber, a inclusão também se constitui como um conjunto de normas que permite seu posicionamento como fenômeno de diferenciação dos indivíduos de uma sociedade. Refere-se ainda, às formas de comportar-se diante da inclusão e em relação a ela. No terceiro eixo, importa olhar para a inclusão na medida em que ela configura certo modo de ser dos sujeitos não incluídos, perante os sujeitos posicionados como incluídos e em relação a eles, considerando que ambos são alvo e condição para a existência dessa matriz de experiência. Desse modo, ao fazer o percurso da história da experiência, interessa analisar as formas de veridicção constituídas historicamente, os procedimentos de governamentalidade, a pragmática de si e as formas que ela adquiriu historicamente (Foucault, 2010a).

Olhando para o enredo brasileiro, pós-promulgação da Constituição de 1988 e em meio às discussões realizadas no cenário mundial ${ }^{4}$, é possível afirmarmos que tais acontecimentos foram fortes condições para que a inclusão pudesse emergir depois, no final da década de 1990. Desde a referida Constituição, vimos crescer e se espraiar, nas comunidades escolares e mesmo entre aqueles não diretamente envolvidos com a escola e a Educação, discursos variados sobre a integração e a inclusão. Diante da crescente necessidade de investir na Educação da população para que a inclusão pudesse se configurar e para que a integração deixasse de ser a diretriz do processo de escolarização das pessoas com deficiência, as campanhas midiáticas - com patrocí-

3. Para uma discussão contemporânea sobre estética da existência, sugerimos a leitura de Rago (2013).

4. Com destaque àquelas realizadas na Tailândia (1990), sobre Educação para Todos, e às realizadas na Espanha que culminaram na Declaração de Salamanca (1994). nio do governo brasileiro e com o apoio de empresas privadas - se fizeram cada vez mais presentes. Tais campanhas colocavam em circulação imagens de pessoas com deficiência na sociedade, com vis- 
tas à educação de todos. Slogans como “inclusão direito de todos" e "ser deficiente é normal” passaram a ser fortemente veiculados, assim como depoimentos sobre sucessos educacionais de experiência de integração ganharam expressão e serviam de testemunhos de sucesso.

Enfim, em meio às campanhas de Estado e aos depoimentos de sucesso da nova empreitada educacional, também eram vistos circular fortes e recorrentes reclamações sobre a falta de preparação docente para trabalhar com alunos com deficiência; sobre as precárias condições escolares para atender as necessidades dos indivíduos que não conseguiam se locomover, se comunicar e aprender; e sobre a proliferação discursiva, geralmente de ordem médica, psicológica, psicopedagógica, psiquiátrica e legal, usada para caracterizar os sujeitos integrados e justificar os insucessos dos escolares com deficiência e a necessidade de um corpo de especialistas capazes de educar aqueles anormais.

Ao pensarmos sobre as muitas práticas pró e contra a integração e o campo tenso em que a inclusão emergiu no Brasil, é possível dizer que, como um dos efeitos da integração, novas lutas foram geradas. Entre tais lutas, está a da necessidade de conviver com o outro de outros modos. Não bastava estar junto com o outro reconhecido como normal (integração); era igualmente importante investir nas relações entre aqueles que passaram a compartilhar os mesmos espaços (inclusão) (Lopes; Fabris, 2013b). Isso significa que, com a inclusão, passaram a circular muitos discursos que borravam as tradicionais fronteiras entre a normalidade e a anormalidade.

Resumindo: até o início dos anos 2000, a inclusão no Brasil não se constituía em uma das prioridades nacionais, muito menos era razão para fortes investimentos da Nação nas condições de vida, educacional e de participação dos sujeitos. Conforme Saraiva e Lopes (2011, p. 17), "estar incluído era simplesmente poder desfrutar dos benefícios que eram estendidos a toda a população." Isso significava que não havia uma preocupação em capacitar os indivíduos, por exemplo, para que eles pudessem prover a si e por si mesmos, outras condições de vida. Com o fortalecimento das investidas do Estado, articuladas aos desejos já desenvolvidos nas pessoas com deficiência e seus familiares, bem como naqueles subjetivados pelas práticas de integração e nas empresas (essas cada vez mais mobilizadas e engajadas na educação da população), compõe-se um enredo em que subjetividades são constituídas em uma atmosfera inclusiva.

Na Contemporaneidade, uma série de saberes encontra condições de emergência na conformação de subjetividades mais abertas e flexíveis. As práticas inclusivas 
alargam-se, fazendo circular verdades em torno das diferenças e das potencialidades dos sujeitos. A crença de que todos são capazes de aprender e criar outras condições de vida para si, a partir do momento que seus interesses são mobilizados, e de que podem se sair melhor a partir da inclusão, gera frentes de ações estatais e não estatais que elevam a inclusão a um imperativo de Estado (Lopes et al, 2010). Trata-se de um imperativo que, ao acessar e ao inventar novas práticas, bem como ao montar distintas estratégias inclusivas, enuncia uma mudança de vida para todos a partir da corresponsabilidade pelo outro e da autorresponsabilização de cada um consigo mesmo.

Diante da ampliação das redes que constituem a inclusão e que a posicionam na história brasileira como uma matriz de experiência que permitirá ao País transpor barreiras econômicas, sociais, educacionais, de saúde, culturais e galgar outras posições de desenvolvimento em um ranking econômico e de desenvolvimento mundial, importa conhecer como essa invenção chegou a tal posição na nossa história recente. Também importa atentar para as mudanças que a configuram, ampliam sua abrangência populacional e a atualizam nos intricados jogos de poder. Para tanto, buscamos em Foucault o que denominamos de inspiração metodológica de abordagem do tema. Isso significa, entre outros aspectos, que, ao tomarmos as lentes foucaultianas, podemos perceber que partimos da exclusão daqueles que eram ignorados pelo Estado para a busca estatística de todos, da reclusão por confinamento para a reclusão, em tempo parcial dos indivíduos considerados em risco social para tratamento, educação, formação para o trabalho, enfim, para a reeducação; e da reclusão em espaços de confinamento parcial do tempo para uma (ainda almejada) inclusão total. Dito de outra forma, na esteira foucaultiana (2003), somos conduzidos a pensar os movimentos da reclusão instaurada no século XVIII - que retirava os indivíduos do convívio social - e da reclusão no século XIX, que teve por função "ligar os indivíduos aos aparelhos de produção, formação, reformação ou correção de produtores" (Foucault, 2003, p. 114). Enquanto, no primeiro modo, vemos uma inclusão por exclusão dos marginais, no segundo modo temos a inclusão e a normalização como fins da reclusão. É sobre este segundo modo, desenhado a partir do século XIX, que nos debruçamos para pensar as condições de emergência de um foco ou matriz de experiência inclusiva e a Educação.

Foucault (2003), ao identificar historicamente movimentos caracterizados como de exclusão, de reclusão e de inclusão, fornece-nos elementos e base de leitura para afirmarmos que, além dos movimentos já mencionados, hoje podemos acrescentar o 
de in/exclusão (Lopes, 2004). Esse último é caracterizado não pela reclusão total ou parcial do tempo da vida dos indivíduos, mas pela expansão da responsabilidade com a Educação para o âmbito social, empresarial e do próprio indivíduo. Todos educam todos, seja por ações diretas e intencionalmente educativas e/ou pedagógicas, seja pela simples presença no millieu social. Portanto, conforme Lopes e Fabris (2013a, 2013b) in/exclusão é a expressão capaz de melhor caracterizar as relações movediças do presente. Para as autoras, ele abarca "tanto a ambiguidade e a ambivalência existente entre os termos integração e inclusão quanto o escorregadio conceito de exclusão (ora entendido como desfiliação, ora como estar emocional e psicologicamente ausente ou ter sua presença ignorada mesmo com o corpo presente) [...]”. (Lopes; Fabris, 2013b, p. 75).

Dentre os efeitos que a teorização foucaultiana nos provoca, para além das ferramentas que minuciosamente são operadas nesse campo e nos apresentam infinitas possibilidades de trabalho intelectual na Educação, arriscamos dizer que um dos maiores efeitos dessa produção está no modo pelo qual o filósofo operou com seu pensamento e mobilizou conceitos, transformando-os em ferramentas. Assim, para desenvolvermos a problematização proposta neste artigo e inspiradas no modo como o filósofo francês conduzia suas pesquisas, examinamos as práticas culturais em sua matriz de constituição histórica. Ao pensarmos a inclusão como experiência implicada na subjetivação dos indivíduos, reconhecemos a complexidade da rede que a compõe e que dá condições para sua existência. Fazendo eco a Foucault, procuramos mostrar esse enredamento, para sustentar a ideia de que a inclusão se torna uma matriz de experiência que movimenta práticas de subjetivação dos indivíduos, para constituí-los sujeitos capazes de conviver com outros e adotar comportamentos considerados inclusivos. Argumentaremos adiante que, ao conformar subjetividades inclusivas, o projeto moderno-democrático-neoliberal maximiza o caráter individual dos sujeitos conferindo-lhes a responsabilidade pela inclusão. Ao fazer isso, acaba por provocar comportamentos inesperados que, por sua vez, podem colocar em risco a própria inclusão como estratégia de ampliar a participação de todos e reduzir as desigualdades sociais.

Ao fazermos uma digressão histórica, é possível visualizar a formação de saberes que normalizam os comportamentos, tendo em vista a economia e a utilidade dos corpos dos indivíduos. No alastramento das instituições de sequestro, são produzidas subjetividades disciplinarizadas cuja relação produtiva é internalizada e conduz 
as ações dos indivíduos e da população. Incluir passa a delinear novas condições possíveis de vida, as quais se fortalecem no século XX e, nos últimos aproximados 20 anos, acabam por constituir uma matriz de experiência.

A inclusão aparece como uma forma de alcançar tanto o coletivo da população - por meio de biopolíticas -, quanto cada indivíduo em particular - por meio das inúmeras operações de disciplinamento e correção das anomalias. A dependência existente entre a noção de biopoder e de população, bem como entre tecnologias disciplinares e de controle, torna-se evidente e produtiva para o Estado promover condições diferenciadas de vida (Lopes; Dal'igna, 2012, p. 855).

Então, ao propormos o entendimento da inclusão como uma matriz de experiência, estamos deslocando o entendimento da inclusão como prática vivida pelos sujeitos, ou seja, como um caso a ser conhecido, relatado e pensado para entendê-la como conjuntos de práticas possibilitadas por redes de relações em que a experiência se constitui como atmosfera de seu tempo. Isso significa que, ao reunirmos e analisarmos pesquisas no campo da Educação e da assistência social sobre inclusão e ao adentrarmos as práticas que possibilitaram a sua emergência, sustentamos que, se a inclusão se impõe a nós no presente por meio das políticas; se ela é uma estratégia para que todos possam compor um gradiente de participação social e econômica (Lopes et al, 2010); se ela é constituída e constitui saberes; se ela é condição para almejar outras performances coletivas e individuais; se ela tanto sujeita quanto subjetiva os indivíduos, é porque ela também cria normativas de comportamento e subjetividades caracterizadas por Menezes (2011) como “inclusivas”.

Porém, pari passu a tudo o que foi mencionado acima, também vemos emergir outros arranjos de vida impensados, mas que também são efeitos da inclusão. Ao prover a aproximação dos indivíduos e ao proporcionar a eles outras condições de vida, também são providas outras tensões, outros arranjos intersubjetivos ainda não subordinados à ordem e aos controles dados. Dessa forma, podemos entender que a proximidade do outro é sempre potência ou condição necessária para, talvez, uma vida outra, mesmo que tal vida seja ignorada e brevemente vivida. Portanto, mesmo entendendo que a inclusão, como um imperativo do Estado brasileiro, esteja na ordem discursiva que sustenta um tipo de racionalidade governamental neoliberal e 
mesmo entendendo a inclusão como uma estratégia pervasiva de Estado, pois ela se entranha na população e nas subjetividades, também é possível afirmar, a partir da noção foucaultiana de "contraconduta" (Foucault, 2008b), que ela possibilita outras condutas e outras formas de condução que não rompem com o princípio do viver com o outro. Resumindo: mesmo que subjetividades estejam à mercê de capturas por práticas includentes ou inclusivas, sempre é possível (simplesmente) viver com o outro e consigo mesmo, sem que a diferença, reduzida na identidade, seja pontuada como um referente para o estar com o outro e usufruir dos direitos de todos. Nas palavras de Rago (2013, p. 43), “esses modos se distanciam da concepção cristã do indivíduo cindido em seu próprio eu, aquele em que a alma tem primazia sobre o corpo”.

\section{A inclusão na era da proliferação das normas}

Tomando ferramentas foucaultianas para pensar a inclusão e submetendo-a a uma crítica radical, voltemos para a sua compreensão como uma "matriz de experiência” que dá os tons da atmosfera em que subjetividades são constituídas. Mostrar a constituição de uma matriz em que experiências convergem para a conformação de uma forma de vida inclusiva permite-nos interrogar o presente como integrante de uma época em que normas de comportamentos instituem e naturalizam o estar junto, no mesmo espaço, como uma condição necessária para certa estabilidade do Estado, embora algumas exclusões se configurem. Ao fazermos um recuo histórico para examinar a proveniência das práticas que funcionam como condições para a emergência de uma matriz de experiência inclusiva, selecionamos alguns recortes de políticas e documentos de caráter oficial produzidos no Brasil, principalmente nas últimas duas décadas, pelo Ministério da Educação. Tais documentos compõem o conjunto de materiais de análise de uma pesquisa mais ampla e aqui serão utilizados no intuito de visibilizar alguns movimentos que levaram a inclusão a uma verdade deste tempo.

Em meados dos anos 1990, emergiram as condições para a composição de um cenário cuja preocupação passou a centrar-se na perspectiva de uma vida inclusiva. Neste contexto, a elaboração de uma proposta de inclusão pressupunha fortemente uma educação corretiva ancorada em saberes médicos, biológicos e psicológicos. Com a criação de normativas legais, como foi o caso da Política Nacional de Educação Especial no Brasil (1994), previu-se a integração instrucional para os alunos com necessidades educacionais especiais que pudessem ser inseridos na turma regular. A Lei de Diretrizes e Bases da Educação Nacional - LDBEN / Lei no 9.394/96, na mesma 
direção, ainda preconiza a valorização das diferentes potencialidades de aprendizagem, principalmente daqueles que não conseguiram atingir o nível de aprendizagem que lhes era exigido. Já as Diretrizes Nacionais para a Educação Especial na Educação Básica - Resolução CNE/CEB nํ2/2001, em seu artigo segundo, determina que todos os alunos devem ser matriculados no sistema comum de ensino, em que todas as escolas precisam se adequar, a fim de viabilizar uma educação de qualidade aos alunos com necessidades educacionais especiais.

Nos anos 1990, temos a Declaração de Salamanca (1994), direcionada a respaldar o acesso, às escolas regulares, das crianças com necessidades educacionais, justificando suas ações na diversidade cultural. Em suas afirmativas, a Declaração expõe normativas que preconizam o direito de cada indivíduo à aprendizagem, colocado no centro da condução pedagógica. Suas individualidades precisam ser consideradas no contexto educativo, de modo a assegurar que suas necessidades e seus interesses sejam contemplados e a participação social, legitimada. Nesse cenário, vemos indicações de práticas focadas em um ideal de educação que alarga as condições de entrada e permanência dos indivíduos no âmbito social e contribui para a proliferação de tipos de normalidades. Cabe destacar que:

- cada criança tem o direito fundamental à educação e deve ter a oportunidade de conseguir e manter um nível aceitável de aprendizagem;

- cada criança tem características, interesses, capacidades e necessidades de aprendizagem que lhe são próprias;

- os sistemas de educação devem ser planejados e os programas educativos implementados, tendo em vista a vasta diversidade destas características e necessidades;

- as crianças e jovens com necessidades educativas especiais devem ter acesso às escolas regulares, que a elas se devem adequar através duma pedagogia centrada na criança, capaz de ir ao encontro destas necessidades (Unesco, 1994, p. 7).

Para disseminar a ideia de inclusão que se fortalece nessa trama histórica, o Ministério Público Federal lançou, entre outros materiais, o documento intitulado $O$ Acesso de Alunos com Deficiência às Escolas e Classes Comuns da Rede Regular (2004), no qual fica reiterado o direito à escolarização de todos. Nessa linha de direcionamentos oficiais, a Política Nacional de Educação Especial - na Perspectiva da Educação Inclusiva (2008) mostra que, entre 1998 e 2006, houve um crescimento de $640 \%$ das matrículas em escolas comuns e apenas $28 \%$ em escolas e classes especiais. A Política parece clamar pela necessidade de ampliar o atendimento escolar no espaço da 
escola comum e, assim, retira o foco no atendimento em escolas especializadas ou classes especiais. Dentre seus objetivos, define:

[...] assegurar a inclusão escolar de alunos com deficiência, transtornos globais do desenvolvimento e altas habilidades/superdotação, orientando os sistemas de ensino para garantir: acesso ao ensino regular, com participação, aprendizagem e continuidade nos níveis mais elevados do ensino; [...] formação de professores para o atendimento educacional especializado e demais profissionais da educação para a inclusão (Brasil, 2008, p. 14).

O movimento inclusivo se fortaleceu e a noção de inclusão no âmbito educacional foi ampliada e apresentada como um problema de Estado e, portanto, um problema cuja responsabilidade deveria ser assumida por todos. A formação de professores para o atendimento aos que precisam ser incluídos torna-se mais generalista e reduz-se o público a ser atendido por profissionais com habilitação específica. Também a inclusão escolar extrapola o campo de saber da Pedagogia e da Educação especial e passa a se constituir em uma bandeira para todos. Os saberes clínicos e biológicos não desaparecem, mas tendem a focar sua atenção em um grupo delimitado e específico de alunos - aqueles com deficiência, transtornos globais do desenvolvimento e com altas habilidades/superdotação. Saberes provenientes de outros campos ganham força; dentre eles, há os saberes de ordem econômica, assistencialista e sociológica. Todos os demais sujeitos da educação devem, a partir de então, ser atendidos no espaço do ensino regular ou comum, como passa a ser nomeado o sistema ou o espaço educacional inclusivo. Os sistemas de ensino são, então, vistos como inclusivos e, portanto, todos os indivíduos devem conviver no mesmo espaço físico.

Nesse cenário, contemplar a equidade pelo respeito às diferenças (traduzidas como diversidade) coloca-se como mote das práticas governamentais na produção de um comportamento transformado e transformador, para o qual todos são convocados a se converter. Assim, a formação de profissionais - e, no caso da Educação, de professores para o trabalho com as diferenças - vem a ser menos especializada e assume uma ênfase generalista, valorizando um tipo de conhecimento panorâmico e abrangente. Direcionamentos oficiais reiteram a diversidade e dão vazão ao caráter transformador dos espaços educacionais e sociais: 
[...] o Ministério da Educação cria o Programa Educação Inclusiva: direito à diversidade, visando transformar os sistemas de ensino em sistemas educacionais inclusivos, que promovem um amplo processo de formação de gestores e educadores nos municípios brasileiros para a garantia do direito de acesso de todos à escolarização, a organização do atendimento educacional especializado e a promoção da acessibilidade (Brasil, 2008, p. 9, grifos nossos).

Fica claro o compromisso assumido coletiva e individualmente para a construção de uma sociedade equânimes. Essa atmosfera, forjada, entre outras práticas, para a constituição de subjetividades inclusivas, permite o aparecimento de uma “matriz de experiência” correspondente à inclusão. Cabe ressaltarmos que a experiência, aqui entendida, não condiz com a vivência de um indivíduo apenas. Não se trata de casos onde são vivenciadas experiências inclusivas, mas se trata, como já dissemos, de uma atmosfera ou de um ambiente de onde os indivíduos emergem, são constituídos e também constituem verdades que alimentam e mantêm um ecossistema em tensão. Dessa forma, não se trata de analisar um ou mais casos isolados de experiência inclusiva, mas de atentar para a consolidação de modos de ser e estar no mundo que podem ser comuns ao tempo presente. Ao afirmarmos que, para se perceber uma matriz de experiência, não é necessário buscar experiências pontuais de vida, salientamos que é possível ver a matriz que opera na atmosfera em qualquer subjetividade narrada.

Ao promover o convívio e a proximidade física entre os indivíduos, a inclusão ancora-se na equidade e potencializa os comportamentos individuais. Tendo em vista que precisa do engajamento dos indivíduos para que funcione de forma econômica e eficaz, o projeto inclusivo passa a criar condições para que aconteçam outras formas de relacionamento entre os sujeitos. Ao investir na subjetivação dos indivíduos, a matriz de experiência da inclusão torna-os capazes de aliar, no domínio de si, práticas de sujeição e práticas de liberdade. 0 agonismo da conjugação dessas práticas, ao mesmo tempo em que captura o indivíduo e o submete à matriz de experiência da inclusão, também possibilita condições de, ao estar junto com outros, criar contracondutas que podem alterar ou deslocar as formas de condução vividas até então. sua relação com a inclusão, vide Veiga-Neto (2010). 


\section{Considerações finais}

No início deste artigo, afirmamos que, embora Foucault não tenha se ocupado especificamente com a Educação, suas teorizações são importantes para nós, na medida em que permitem que problematizemos as distintas formas de subjetivação e as formas de condução das condutas dos indivíduos. Entendemos que a ação educacional é imanente à ação de governamento ou de condução das condutas. Portanto, toda a ação de educação é uma ação de condução do outro a tornar-se algo que ele não era antes.

Assim, pensar os efeitos Foucault no campo da Educação não é algo necessariamente difícil, embora seja complexo, pois, nos muitos processos de tornar-se sujeito, podemos ver as contribuições do filósofo.

Neste artigo intentamos utilizar, para o tensionamento da Educação e, mais especificamente, para a problematização da temática da inclusão, algumas ferramentas conceituais profícuas para entendermos como a inclusão, hoje no Brasil, assume o status de matriz de experiência. Dito de outra forma, é interessante examinar como a inclusão, ao se deslocar da ideia de reclusão, passa a operar de maneira distinta, voltada não só para a Educação e constituição de tipos específicos de sujeitos, mas também para a educação de todos e o governo do social.

As muitas normativas, os rituais inclusivos, a mobilização da maquinaria escolar pró-inclusão e aprendizagem de todos, os testemunhos de sucesso, o crescente número de especialistas e de conhecimentos produzidos sobre o sujeito, etc. são parte de um complexo jogo constitutivo de um tipo de racionalidade governamental capaz de se recriar constantemente, visando sempre abarcar mais um membro em suas tramas. Então, se a inclusão é uma das condições de manutenção de uma ordem contemporânea, ela também pode ser, pelos processos de intersubjetivação, uma condição para a criação de contracondutas. Portanto, assim como a matriz de experiência da inclusão gera subjetividades inclusivas, ela também pode gerar outras subjetividades impensadas e outras conduções que não se colocam necessariamente contra a inclusão.

Para finalizar, recorremos à pergunta de Gadelha (2009, p. 214): "de que vale a inclusão se ela não constituir, ao mesmo tempo, um ato de resistência?”. A inclusão como matriz de experiência vale porque, além de possibilitar outra economia com a aproximação de uns aos outros, e de que todos usufruam dos mesmos direitos e que haja maior fluidez e controle dos riscos sociais que podem ser constantemente mapeados e acompanhados, também possibilita, ao colocar todos juntos, subjetividades outras, vidas outras e ações outras, mesmo que sejam rápidas, fugidias, ativistas e de contracondutas. 


\section{Referências bibliográficas}

AQUINO, Julio Groppa. A difusão do pensamento de Michel Foucault na educação brasileira: um itinerário bibliográfico. Revista Brasileira de Educação, Rio de Janeiro, v. 18, n. 53, p. 301-324, abr./jun. 2013.

BRASIL. Ministério da Educação. Lei de Diretrizes e Bases da Educação Nacional - Lei no 9.394., Brasília: Ministério da Educação, 1996.

BRASIL. Ministério da Educação. Secretaria de Educação Especial. Política Nacional de Educação Especial. Brasília: MEC/SEESP, 1994.

BRASIL. Ministério da Educação. Secretaria de Educação Especial. Política Nacional de Educação Especial na perspectiva da educação inclusiva. Brasília: MEC/SEESP, 2008.

BRASIL. Ministério Público Federal. O Acesso de Alunos com Deficiência às Escolas e Classes Comuns da Rede Regular. 2. ed. Brasília: Procuradoria Federal dos Direitos do Cidadão, 2004.

FOUCAULT, Michel. A hermenêutica do sujeito. São Paulo: Martins Fontes, 2004.

FOUCAULT, Michel. A verdade e as formas jurídicas. Rio de Janeiro: NAU, 2003.

FOUCAULT, Michel. Do governo dos vivos. São Paulo: Rio de Janeiro: Achiamé, $2010 a$.

FOUCAULT, Michel. O governo de si e dos outros. São Paulo: Martins Fontes, 2010b.

FOUCAULT, Michel. O nascimento da biopolítica. São Paulo: Martins Fontes, 2008a.

FOUCAULT, Michel. Segurança, território e população. São Paulo: Martins Fontes, 2008b.

GADELHA, Sylvio. Governamentalidade, biopolítica e educação. Belo Horizonte: Autêntica, 2009.

LOPES, Maura. A inclusão como ficção moderna. Pedagogia: A Revista do Curso, UNOESC, São Miguel do Oeste, v. 3, n. 6, p. 7-20, 2004.

LOPES, Maura; DAL'IGNA, Maria Cláudia. Subjetividade docente, inclusão e gênero. Educação \& Sociedade. Revista de Ciências da Educação, Campinas, v. 33, n. 120, p. 851-868, jul./set. 2012.

LOPES, Maura et al. Inclusão e biopolítica. Cadernos IHU Ideias. UNISINOS: São Leopoldo ano 8, n.144, 2010.

LOPES, Maura. FABRIS, Eli. (Org.). Inclusão e biopolítica. Belo Horizonte: Autêntica, $2013 a$.

LOPES, Maura; FABRIS, Eli. Inclusão e educação. Belo Horizonte: Autêntica, 2013b. 
MENEZES, Eliana C. P. A maquinaria escolar: na produção de subjetividades para uma sociedade inclusiva. 2011. 189 f. Tese (Doutorado em Educação) - Universidade do Vale do Rio dos Sinos, São Leopoldo, 2011.

RAGO, Margareth. A aventura de contar-se - feminismos, escrita de si e invenções da subjetividade. Campinas: Editora da UNICAMP, 2013.

SARAIVA, Karla; LOPES, Maura. Educação, inclusão e reclusão. In: Currículo sem Fronteiras, v. 11, n. 1, p. 14-33, jan./jun. 2011. Disponível em: 〈www. curriculosemfronteria.org>.

UNESCO. Declaração de Salamanca e Linhas de Ação para satisfazer Necessidades Educativas Especiais. Salamanca, Espanha, 1994.

UNESCO. Declaração mundial de educação para todos. Plano de ação para satisfazer as necessidades básicas de aprendizagem. Tailândia, 1990.

VEIGA-NETO, Alfredo. Coisas do governo... In: RAGO, Margareth; ORLANDI, Luis; VEIGANETO, Alfredo (Org.). Imagens de Foucault e Deleuze: ressonâncias nietzschianas. Rio de Janeiro: DP\&A, 2002. p. 13-34.

VEIGA-NETO, Alfredo. Equidade e Currículo. In: COLÓQUIO LUSO-BRASILEIRO SOBRE QUESTÕES CURRICULARES, 5., 2010, Porto. Anais... Porto: Universidade do Minho, 2010.

Submetido à avaliação em 29 de novembro de 2013.

Aprovado para publicação em 11 de junho de 2014. 
194 